\title{
RAPID EVALUATION OF MAINTENANCE PROCESS USING STATISTICAL PROCESS CONTROL AND SIMULATION
}

\author{
Petrovic, S. ; Milosavljevic, P. ${ }^{* *} \&$ Lozanovic Sajic, J.*** \\ *Serbian Ministry of Defence, Army Logistic Department, Serbia \\ ${ }^{* *}$ Mechanical Engineering Faculty, University of Nis, Serbia \\ ${ }^{* * *}$ Faculty of Mechanical Engineering, Innovation Centre, University of Belgrade, Serbia \\ E-Mail: saskop@eunet.rs, pedja@masfak.ni.ac.rs, jlozanovic@mas.bg.ac
}

\begin{abstract}
There are successful and less successful maintenance systems (MS). As a dynamic category, the success of the maintenance function must be taken into consideration both for the present day and the future. This is the reason why it is necessary to continuously evaluate, improve and redesign MS. Business process modelling is a good methodology for this purpose. A business process model basically encompasses a formal description of the concept of the system, evaluation methods and process improvement techniques. This paper presents a concept of MS evaluation by using statistical process control in connection with performance indicators and MS improvement by modelling and simulation system. The maintenance model is used for simulation and experimentation. The simulation helps to visualise, understand, analyse and improve processes. The proposed concept is extendable and could be applied in different MS.

(Received in August 2017, accepted in October 2017. This paper was with the author's 1 month for 2 revisions.)
\end{abstract}

Key Words: $\quad$ Maintenance, Evaluation, Process Model, Simulation

\section{INTRODUCTION AND LITERATURE REVIEW}

In engineering, maintenance is generally oriented toward eliminating consequences of failures in contrast to other branches that exploit cutting-edge achievements in designing new products or services. Nevertheless, maintenance seeks the best managerial, technical, technological and organisational accomplishments with the aim of developing powerful strategies dedicated to high equipment availability, numerical analyses, data mining, failure probabilities, cost and risk reducing, and resources and inventory management.

In the science, maintenance is recognized as a one of the most important business processes and it is a subject of constant improvement and optimization. In this area, a lot of the proposed maintenance policies/concepts and optimisation methods are difficult to apply in daily practice. Some of the reasons are: technological diversity (machines, equipment), high level of abstraction, mathematical complexity of proposed models, focus on specific equipment and general motivation for cost reduction. Many of the proposed optimisation methods are not universal but are oriented toward specific equipment or plant. In other words, the problem of maintenance control increases constantly. Even by using the most advanced techniques, high complexity systems cannot be controlled and improved considerably [1].

Because we are the witnesses of the existence of many maintenance policies and strategies, there is a real problem when evaluation/improvement is needed. Our research concentrates on finding new methodology for rapid maintenance evaluation, improvement (if possible) and determination of the future state for a real or imaginary/simulated maintenance system. We believe that this is a comprehensive and universal approach. This attitude relies on a study of more than 150 papers and books on the topic of maintenance, mostly published in the last decade, with the structure of these papers illustrated in Fig. 1. Firstly, we performed an MS evaluation (performance measurement), then designed an MS model, and finally used 
the simulation for MS based on the data obtained from the evaluation process. The simulation proved to be a possible direct optimization method.

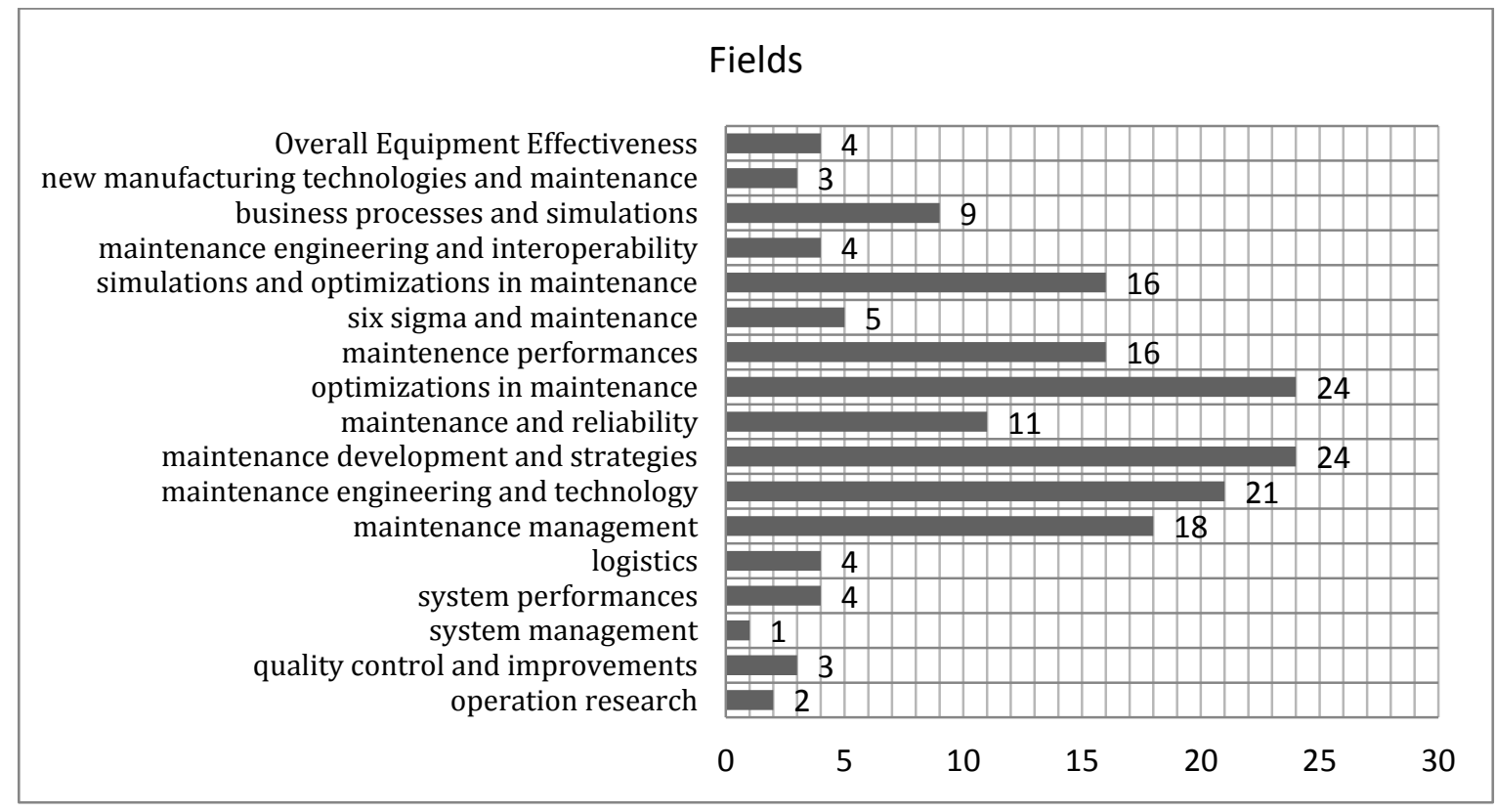

Figure 1: Literature study by fields.

\subsection{Literature review}

In science, maintenance is a thoroughly explained and extremely relevant area. There are a large number of publications, but most are oriented toward some specific problem. Generally speaking, maintenance is described as a business function that supports the basic business process. Different maintenance approaches are the result of diversified technologies and industrial fields. It can be concluded that maintenance is subject to continuous reviews and improvements. Also, maintenance is a problem of technology, organization and management [2-8].

Regardless of how it is organized, the aim of maintenance is to achieve the required result. Authors generally agree that a maintenance system is best assessed by determining or measuring maintenance performances. Since maintenance is influenced by a large number of variables, the problem of measuring performance is most often solved by the indicator's assessment [9-16].

However, the problem of selection of indicators that describe the performance of maintenance and methods of their determination, regardless of the fact that they are defined by a special standard (EN 15341), is also present and relevant. A general approach to the business process and a specific approach from the aspect of maintenance is a good methodology for overcoming this problem. Business process modelling encompasses the description of the system, and some of its most important goals are the evaluation and improvement of the system [17-21]. One of the best accepted techniques for assessing the ability and stability of the process is Statistical process control - SPC [22-24].

Process assessment is also carried out with the aim of improving the process. Complex processes are desirable when improvements are concerned. Therefore, modern techniques are required to provide variation checks when some system is an object of improvement in order to avoid possible mistakes and risks. Simulations are part of business process modelling, operation research and optimization [25-32]. 


\section{MAINTENANCE EVALUATION}

\subsection{Why and what to be measured and how}

Maintenance is defined as a set of numerous technical and related managerial actions carried out to prevent failures or to repair the failed component of a machine, device or software. A maintenance system is usually a subsystem of a larger production or organizational system. Every complex system with many correlated subsystems is difficult to control.

This is the reason why organizations must continuously work on improving processes and decreasing costs and waste. Results should be analysed using different procedures and tools in order to develop and implement effective improvements. A new requirement of "continuous improvement" in ISO 9001 recommends that organizations collect and analyse data on process performance using internal performance indicators and customer feedback. In addition, assets/systems are becoming very complex. Even though problem identification is becoming more rigorous, the ability to solve problems is not necessarily improving at the same rate. Various tools and techniques that are available range from simple checklists and spreadsheets to sophisticated modelling software that is useful in problem solving [2].

The academia and industrial environment have examined numerous maintenance policies and strategies, and plenty of maintenance strategies that are in use today supporting both reactive and proactive maintenance actions. Proactivity is a modern approach [4]. Research papers show that nowadays there are many approaches to maintenance organization in different industrial areas [6]. All these approaches cause a confusion in using basic maintenance terms such as: maintenance strategy, policy, concepts, types, etc. For this reason we will take into account the term classification as shown in Table I. This structure has had a dynamic progress and expansion, especially after WW2 to the present day [3]. Efficiency measurement is an essential task in management, as it not only shows the past, but also indicates directions for future changes [16].

Table I: Maintenance terminology by [21].

\begin{tabular}{|c|c|c|c|}
\hline Action & $\begin{array}{l}\text { Corrective/ } \\
\text { reactive }\end{array}$ & \multicolumn{2}{|c|}{ Predictive, preventive and proactive } \\
\hline \multirow{2}{*}{ Policy } & \multirow{2}{*}{$\begin{array}{l}\text { Failure based } \\
\text { maintenance } \\
\quad(\mathrm{FBM})\end{array}$} & $\begin{array}{l}\text { Drop-out maintenance } \\
\text { (DOM) }\end{array}$ & $\begin{array}{c}\text { Time based maintenance } \\
\text { (TBM) }\end{array}$ \\
\hline & & $\begin{array}{c}\text { Condition based } \\
\text { maintenance }(\mathrm{CBM})\end{array}$ & $\begin{array}{l}\text { Opportunity based } \\
\text { maintenance (OBM) }\end{array}$ \\
\hline Concepts & \multicolumn{3}{|c|}{$\begin{array}{l}\text { Reliability centred maintenance-RCM } \\
\text { Total productive maintenance-TPM } \\
\text { Risk based maintenance-RBM } \\
\text { erized maintenance management system-CMMS } \\
\text { Life Cycle costing-LCC, etc. }\end{array}$} \\
\hline
\end{tabular}

According to [5], industrial engineering techniques deal with two problems: analysis of current processes and/or process improvement.

With two broad categories, efficiency and effectiveness (E\&E), maintenance could be described as a successful or unsuccessful system. Hence, maintenance activities need to be supervised, controlled, measured and improved periodically to produce an effective system. A right and effective performance measurement system is needed for this reason. A maintenance performance measurement (MPM) system is needed to monitor complete activities and for improvements [9]. 
Also, for developed maintenance strategies, it is vital to estimate their E\&E level. As a complex multidisciplinary system, maintenance has a large number of inputs and outputs, and its performance and productivity must be measured with a consistent methodology. According to [10] MPM is defined as "the multidisciplinary process of measuring the value created by maintenance investment, and taking care of the organization's requirements viewed strategically from the overall business perspective". Performance is measurable with indicators. An MPM system is linked to overall performance tendencies and could be used to recognize business processes, areas, departments, etc., that need improvement.

Dimensions of maintenance performance can be diverse, such as technical, economic, human resources, safety etc. The least exploited measures cover several parameters, such as training/learning, skills/competencies, work motivation, process performance and ability, resource utilization, maintenance capacity [11-13].

The future tendencies are associated with the rise in the equipment availability and capacity utilization. Also, the new trends in MPM are the maintenance process and activity mapping and "big data" in maintenance with the purpose of identifying the maintenance performance killers and drivers [15].

\section{BUSINESS PROCESS APPROACH}

\subsection{Business process model}

In a continuous effort for process improvement, over the past ten years there have been attempts to capture the operation of main businesses and use them as a foundation for process improvement. Still, this work has been committed to modelling reliance among the activities. Business process models stereotypically and very often do not take into account the resource (i.e., who is to work or material capacity) or model it extremely simply [17].

A business process (BP) is a set of activities required for a new product or service. A business process model (BPM) is a formal description of resources, material (energy) and data, which participate in a specific business process, and embedded rules and regulations. The simulation in BPM helps to visualise, understand, analyse and design business processes. Usually, simulation in BP is a discrete event simulation (DES). The mathematical/logical model represents a physical system, with the state change in time, by a series of discrete events $[18,19]$. A good example of how business process improvement works on maintenance management is given in [20].

\subsection{Tool for E\&E measurement: statistical process control}

Statistical process control (SPC) is a methodology based on statistics and it is a matter of process control and effectiveness measurement. Statistically based tools and techniques are used for to control and improve processes. Any process is a transformation of different inputs (e.g. materials, operations, actions), into desired outputs (products, information and services). SPC depends on various recorded data, and any organization that wants to apply SPC needs a data recording system. For data interpretation, SPC includes a wide range of well-defined tools such as: process flowcharting (what is done); check sheets/tally charts (how often it is done); histograms (pictures of variation); graphs (pictures of variation with time); Pareto analysis (prioritizing); cause and effect analysis/Ishikawa diagram (what causes the problems); scatter diagrams (exploring relationships); control charts (monitoring variation over time) $[22,23]$.

The key tool associated with SPC is the control chart [24]. It is primarily used to determine if the process is under control. It is also a tool for checking the ideas on what causes problems in the process. 


\subsection{Tool for improvement: simulation}

While studying optimization in maintenance was organized long ago, the simulation-based optimization in maintenance is a new trend. Simulations were used as a tool to produce functionality and for experimentation. The use of a simulation and optimization engine enables the possibility to solve different kinds of problems in maintenance. DES is a popular technique for maintenance systems modelling [25, 26].

Generally speaking, simulations and related methods belong to optimization techniques, as shown in Table II. Optimization is a process with the aim of achieving best possible results under realistic considerations. In maintenance systems, simulation is applied for two main purposes: for understanding, comparison and evaluation; and for becoming an optimal problem solution as simulation together with an independent optimization algorithm.

Table II: Optimization techniques, based on [27].

\begin{tabular}{|l|l|l|l|}
\hline \multicolumn{1}{|c|}{$\begin{array}{c}\text { Mathematical } \\
\text { programming or } \\
\text { optimization techniques }\end{array}$} & $\begin{array}{c}\text { Stochastic process } \\
\text { techniques }\end{array}$ & Statistical methods & $\begin{array}{c}\text { Modern or non-traditional } \\
\text { optimization techniques }\end{array}$ \\
\hline Calculus methods & $\begin{array}{l}\text { Statistical decision } \\
\text { theory }\end{array}$ & Regression analysis & Genetic algorithms \\
\hline Calculus of variations & Markov processes & $\begin{array}{l}\text { Cluster analysis, } \\
\text { pattern recognition }\end{array}$ & Simulated annealing \\
\hline Nonlinear programming & Queuing theory & Design of experiments & Ant colony optimization \\
\hline Geometric programming & Renewal theory & $\begin{array}{l}\text { Discriminate analysis } \\
\text { (factor analysis) }\end{array}$ & Particle swarm optimization \\
\hline Quadratic programming & Simulation methods & & Neural networks \\
\hline Linear programming & Reliability theory & Fuzzy optimization \\
\hline $\begin{array}{l}\text { Network methods: CPM } \\
\text { and PERT and other }\end{array}$ & & & \\
\hline
\end{tabular}

A very limited number of papers survey prognostic methodology in maintenance. It can only be assumed what kind of possibility would have an organization that could predict a breakdown occurrence. Moreover, DES can enable the understanding of the behaviour of a complex maintenance operation with included resources (people, machinery, and material), locations and whole maintenance logistics.

Optimization in connection with simulation has low impact, especially in the areas of operations and staffing. Field maintenance is also an undiscovered area in the sense of DES [28]. Examples of how simulation is used for the optimization purpose in maintenance are demonstrated in [25, 28-30].

\subsection{Case study: E\&E measurement}

One example of a complex maintenance system is an Army maintenance system. Heterogeneous equipment, aged and most modern, hierarchical organization, geographical dispersion, and different missions are decisive factors for the maintenance system. In this case, maintenance evaluation and improvement is not an easy task.

Three-year maintenance data for 30 wide equipment groups (vehicles, weapons, $\mathrm{C}^{2}$ equipment, communication devices, etc.) were collected and analysed. The data were related to: number of maintained equipment by type, activities by maintenance type (prev. /corr.), maintenance frequency, repair time frequency, maintenance personnel availability (by number) and different units. This data were exact. Delay (logistic) time, spare parts 
availability and cost, maintenance personnel reliability, intensity of usage were estimated as well, but this was also based on real data in the form of average value.

Table III: Data structure.

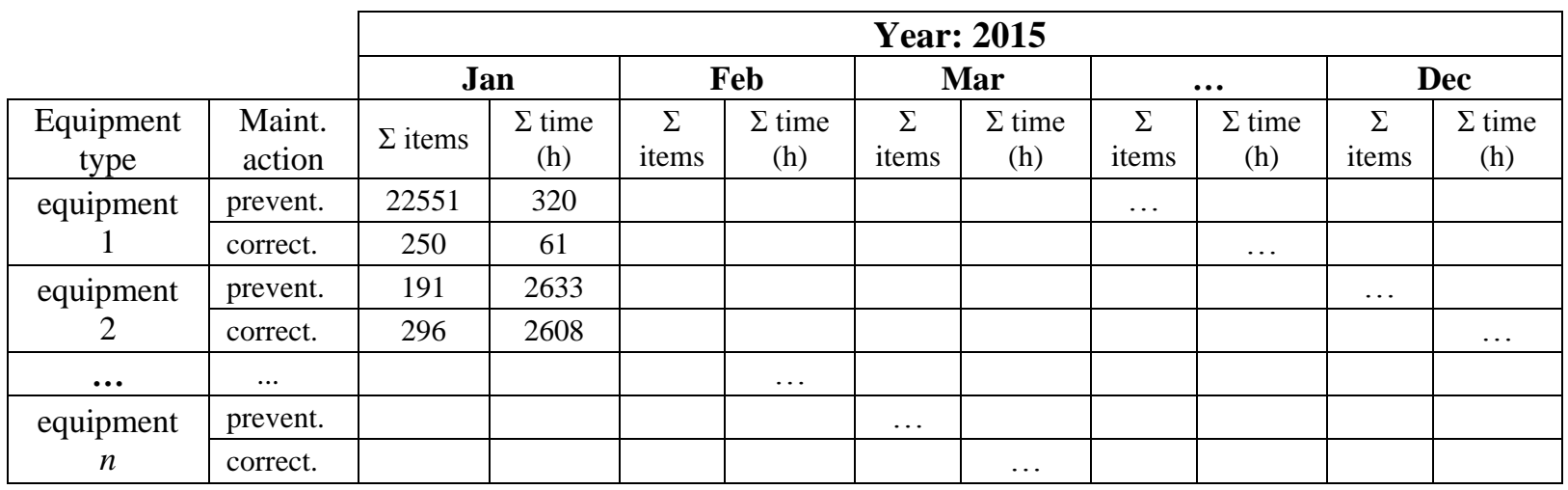

After collecting, the data were organized in proper form, as exemplified in Table III. We used the control charts described in the SPC chapter. Two important key performance indicators (KPIs), number of maintenance actions (corrective and preventive) and total repair time (corrective and preventive) during the time were analysed. These two categories strongly described the maintenance system, not in its entirety, but sufficiently for stability and capability estimation. Figures (see Figs. 2 and 3) below show the illustrations of control charts for 3 different types of equipment (infantry weapons, heavy weapons, vehicles, for one Army unit, e.g. army brigade).

Control charts (see Figs. 2 and 3) are well known for displaying the individual value and the moving range for the analysed process parameters. Variations of maintenance actions are displayed in Fig. 2 and repair time duration is displayed in Fig. 3 for preventive and corrective maintenance. Control charts indicate the instability of the maintenance process for some equipment (e.g. vehicles) and this is the reason behind the need for improving.
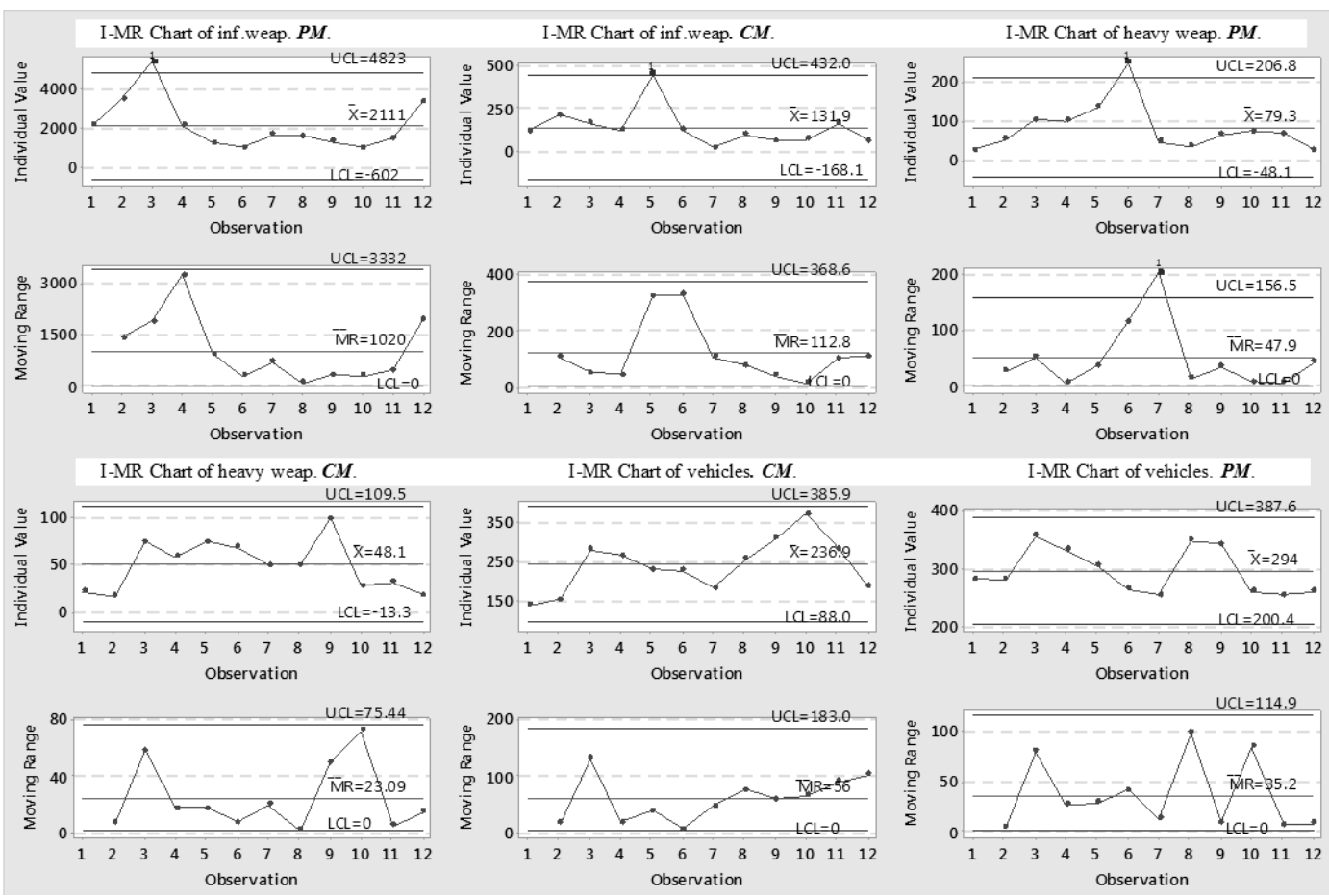

Figure 2: Control chart X/MR (I-MR) (number of maintenance actions over time, 12 months period, preventive maintenance actions PM and corrective maintenance actions $\mathrm{CM}$ ). 

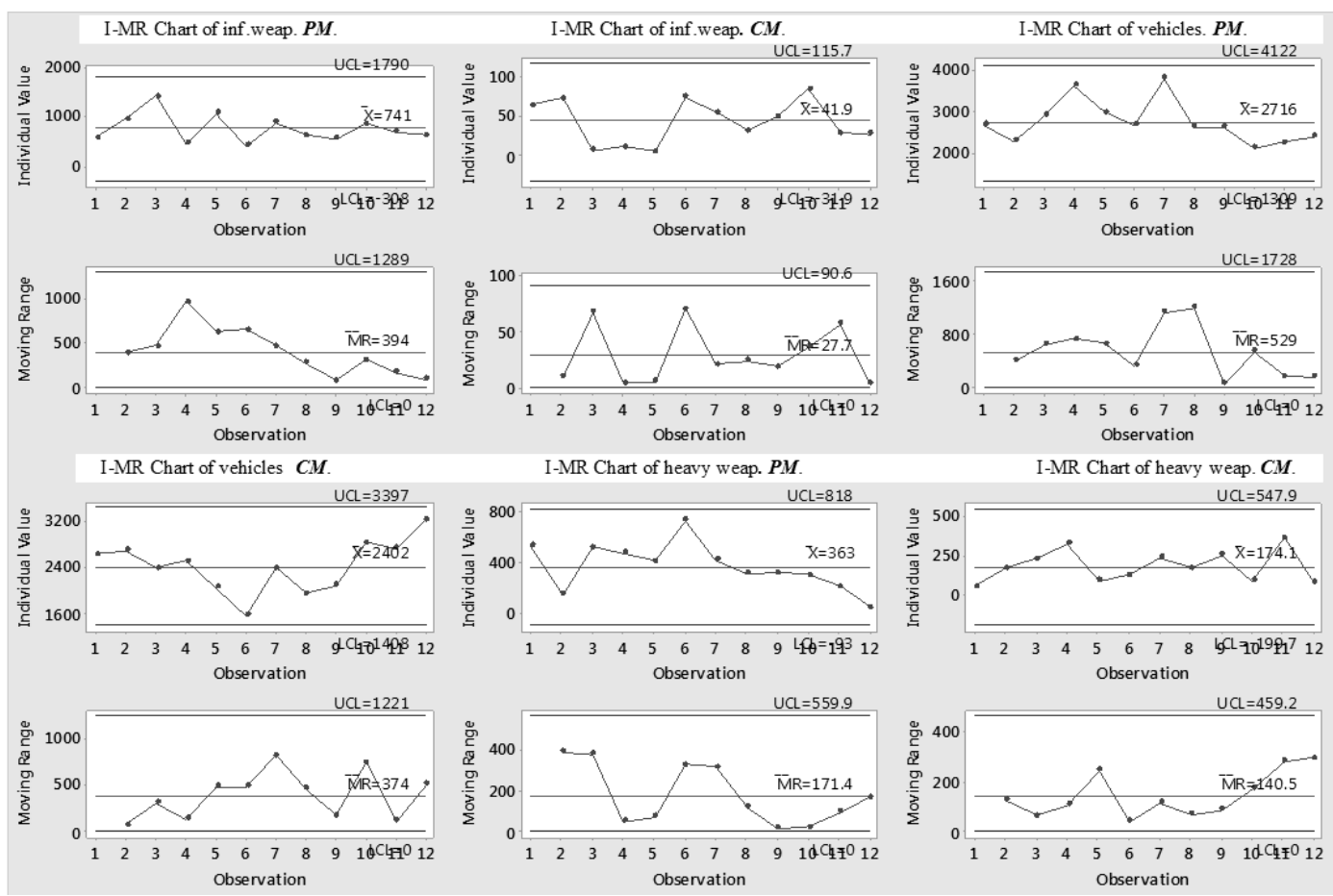

Figure 3: Control chart X/MR (I-MR) (total repair time, 12 months period, preventive maintenance actions PM and corrective maintenance actions $\mathrm{CM}$ ).

After this, we focused our research on vehicles maintenance. Now, we extended the period of analysis to 36 months. The next figure (see Fig. 4) illustrates the result. The control chart (number of maintenance actions over time-by month, preventive actions and corrective actions; total repair time by month, preventive actions and corrective actions, 36 months period) shows variations in the monthly number of maintenance actions during a three-year period, preventive actions and corrective actions. Also, this figure is an example of how repair time spending fluctuates over a period, for preventive and corrective maintenance actions in the same period.
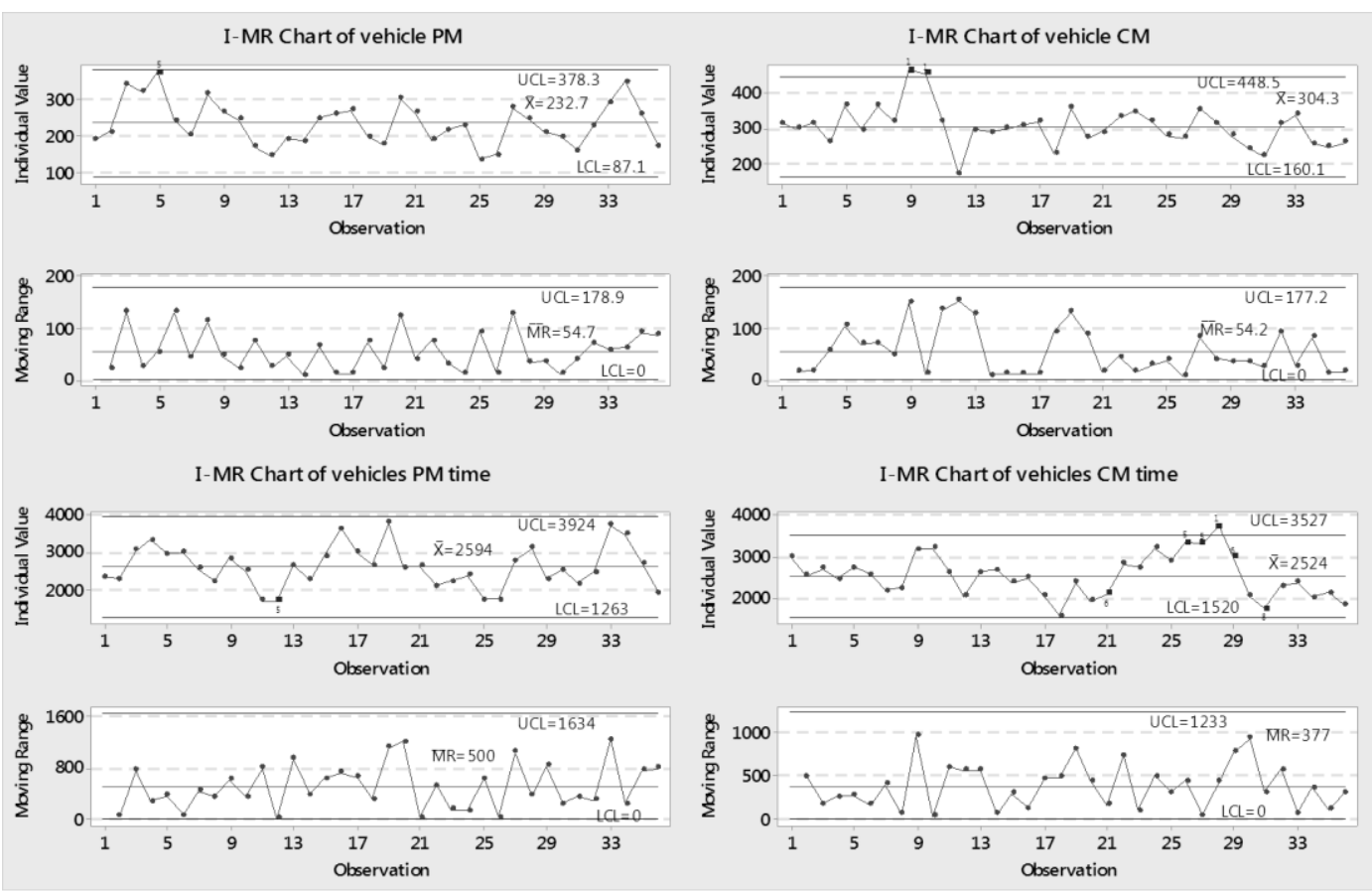

Figure 4: Control chart X/MR (I-MR), analysis of the maintenance system for 36 months, vehicles. 
Then, we looked for a clearer picture of the behaviour of the maintenance system. Fig. 5 (distribution of maintenance actions over time, vehicles, preventive actions and corrective actions; distribution of maintenance duration over time, vehicles, preventive actions and corrective actions; distribution of vehicle inputs in maintenance system over time, vehicles, preventive actions and corrective actions) shows in the form of a histogram how many vehicles appear in the maintenance system per month (36 months period) and how long preventive and corrective maintenance actions last. Finally, we were interested in finding out the shortest time base of the appearance of vehicles in the maintenance system, which is also illustrated in the form of a histogram.

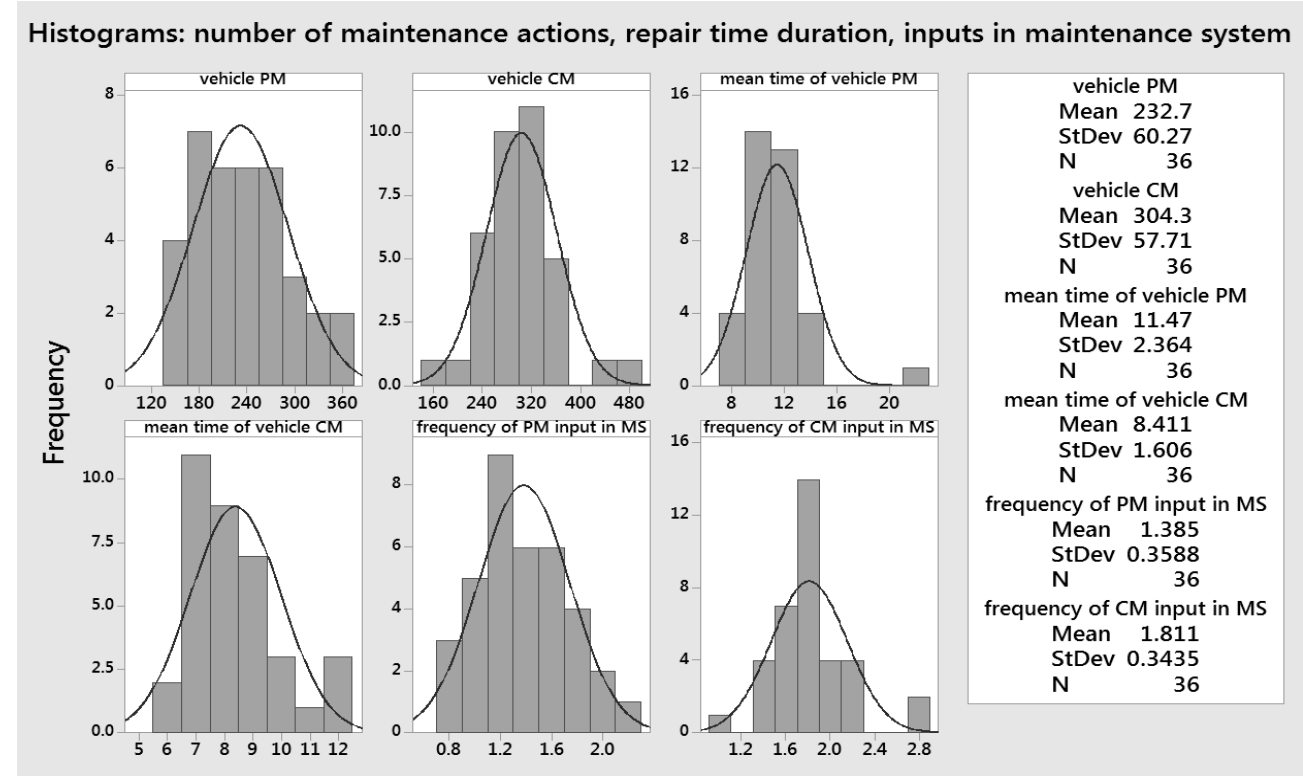

Figure 5: Histogram, (analysis of the maintenance system for 36 months, vehicles).

This measurement and evaluation is not only in the function of deciding whether the maintenance process is stable and capable or not. Moreover, various measured event (time) distributions are crucial for the following simulation (discrete event simulation). The present view treats the maintenance system as a black box and the next section presents a complete analysis of the maintenance system with all its influencing factors.

\section{PROPOSED SOLUTION}

\subsection{Simulation study}

The simulation study begins with the model design. The model is the representation or imitation of the real world. The model is a simplified picture of the real world, with certain simplifications and approximations. The model, Figs. 6 and 7, represents the flow of energy, material, people and information with defined interconnections.

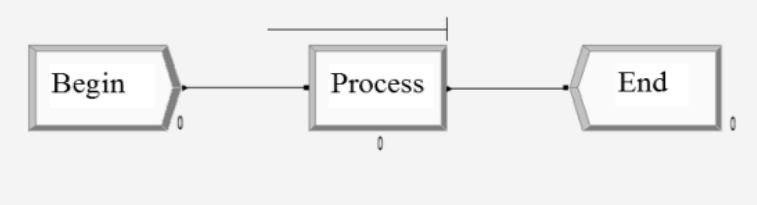

Figure 6: Elementary maintenance system model and simulation model (beginning, a transformation process, end). 


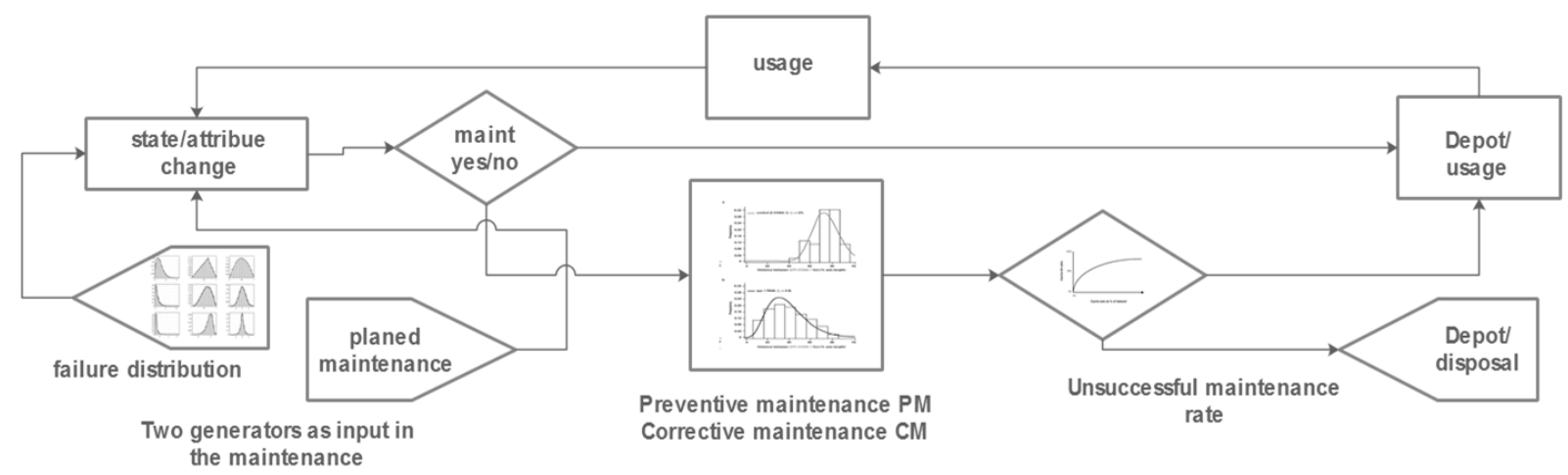

Figure 7: Simple maintenance model.

The basic subject in the maintenance model is a unique type of equipment (e.g. truck). Further characteristics or attributes could be connected to this equipment (user, basic location, item condition, time of creation, etc.). These characteristics could be changed during the simulation. When the simulation is executed, these types of equipment, called entities, pass through different modules and different well-defined actions. The entity waits because of logistic delays (administrative works, spare parts and material availability, transport etc.). After these actions are synchronized, resources (people, machines, equipment) take action over the entity. Resources are also well-defined by number, availability, failures, and work type. Cost of activities and material is also defined. The number of entities and entity types is unlimited (it depends only on the simulation software limitations). When the model is created, verified and validated, the level of effectiveness of our maintenance system is examined by using KPIs. By using the expression builder (see Fig. 8) the value of KPIs (see Fig. 9) is defined by an equation.

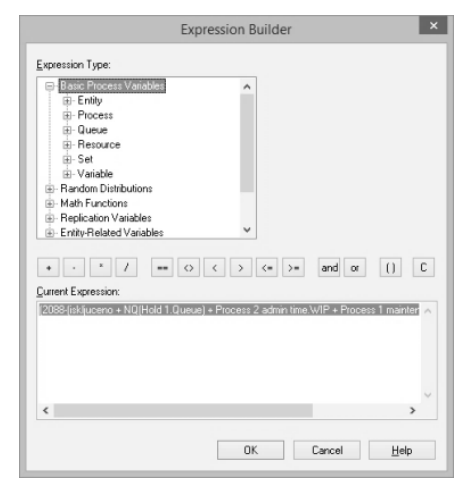

Figure 8: Expression builder.

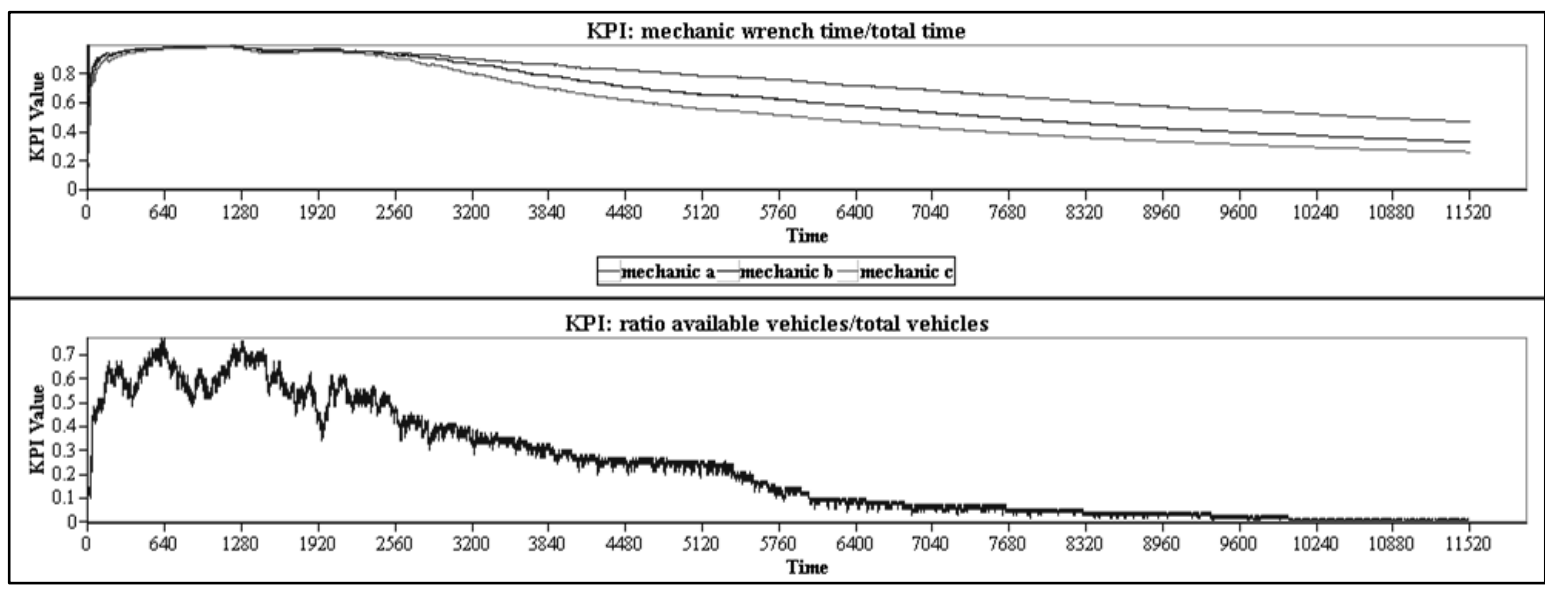

Figure 9: Different KPIs (value 0 to 1), dynamic calculation during simulation, illustration. 


\subsection{Model}

The design of the model depends on the used tool. Every commercial tool has specific, unique characteristics. We used a student version of Arena Simulation $\subset$, version 15, in accordance with the rules of usage. In our model, we examined the maintenance system by two parallel processes that were carried out at the same time: corrective $(\mathrm{CM})$ and preventive maintenance (PM). In the corrective channel, entities (one piece of equipment) occur (input in maintenance system) by determined distribution (frequency). When an entity occurs, it requires a various delay time to be processed in the workshop. Naturally, spare parts are required for a successful repair. Only when an entity (piece of equipment) and spare parts are matched, the further step - action in the workshop, is possible. If too many entities wait for parts, a specific number of entities are removed from the maintenance system by the defined rule. They are sent to the temporary depot where they wait for parts, or they are sent to another maintenance system (e.g. outsourcing maintenance). In the preventive channel, the entity also occurs by the defined rule (distribution law) but different from the corrective channel. The coordination between incoming entities in the maintenance system and spare parts is better than in the corrective channel due to the better planning. The resources in the workshop, the same for both channels, are adjusted by number, availability, repair time duration, rules of engagement and work priority. The cost of activities and spare parts is included. Our model is illustrated in Fig. 10.

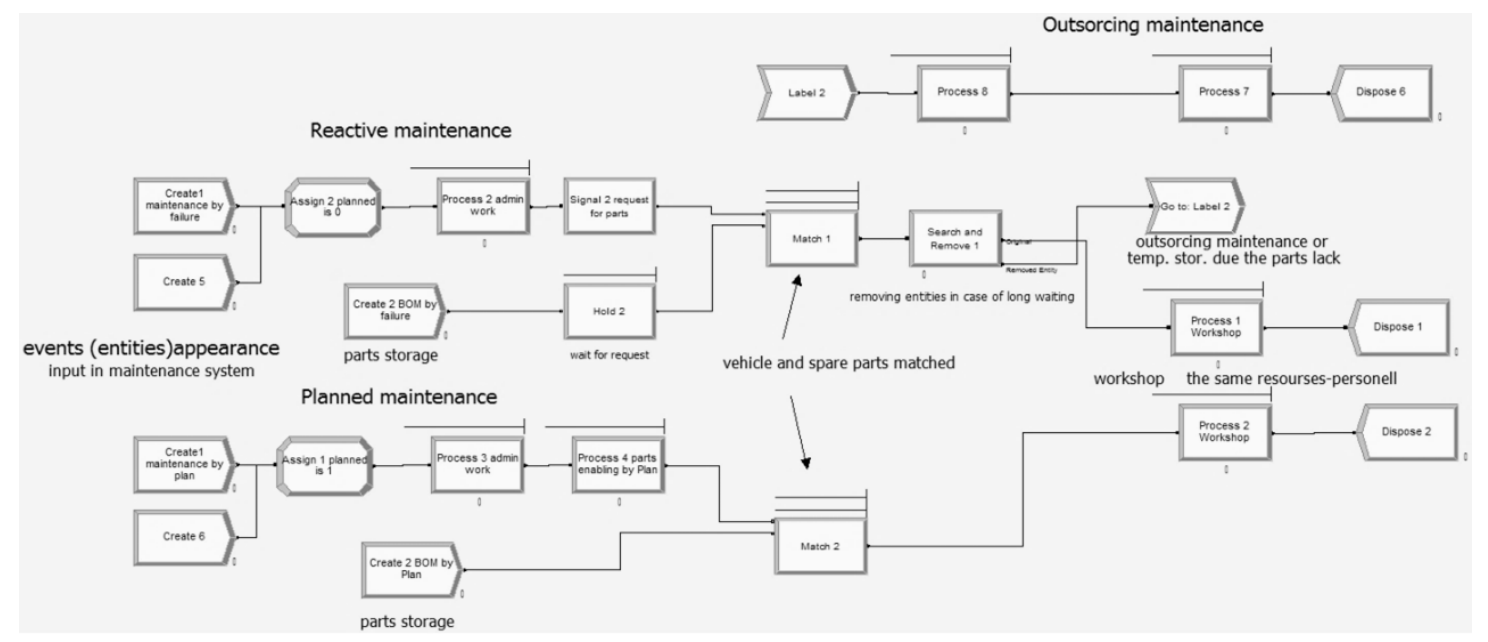

Figure 10: Maintenance system model.

The model is successfully checked by validation and verification. Then, a simulation experiment is performed, and various states are examined. It clearly shows when the system is stable or unstable (by equipment availability criteria). More different criteria are applicable. As an illustration, with a different resources setup, fleet availability and resource utilization (as KPIs) are displayed (the period is one year) in Figs. 11 and 12.
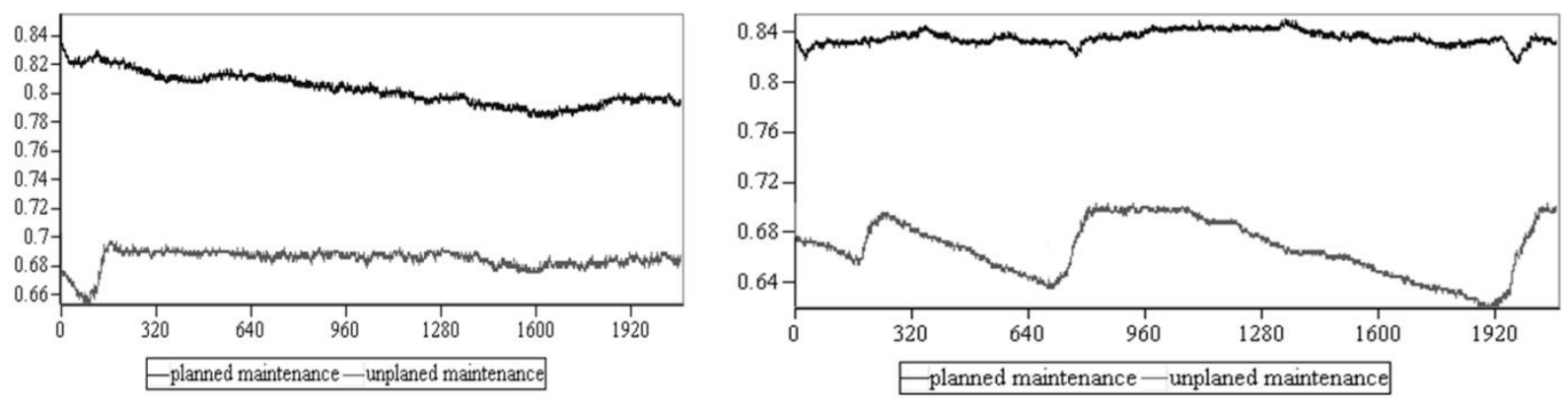

Figure 11: Availability vs. time, resource mode 1 vs. mode 2 (PM-upper line vs. CM). 

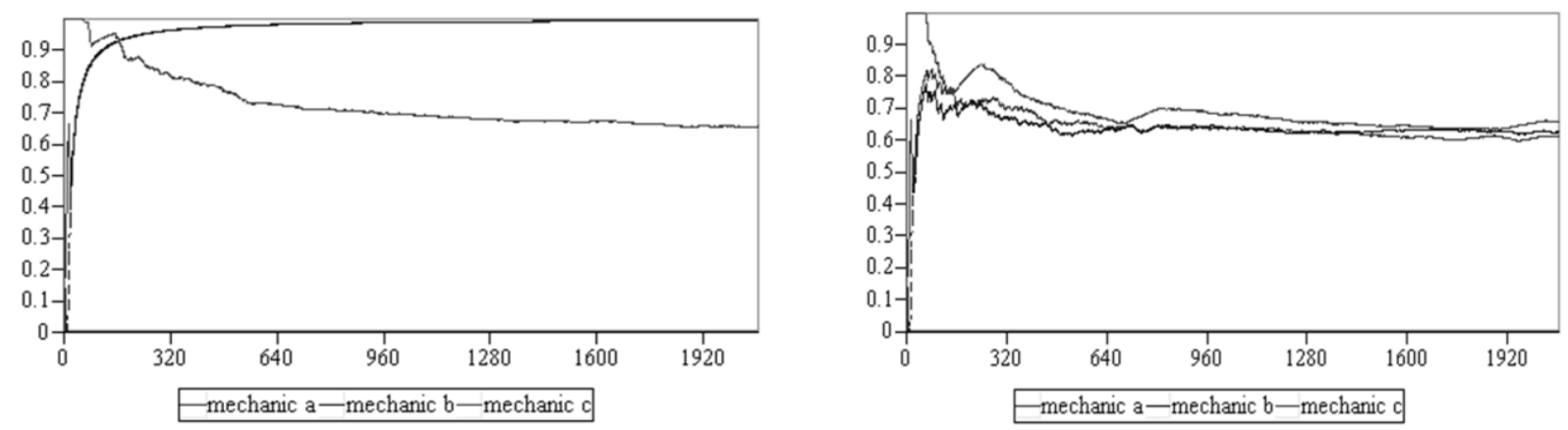

Figure 12: Resource utilization vs. time, mode 1 vs. mode 2.

\section{DISCUSSION}

With the holistic approach, specific maintenance system analysis is done in four steps. The measurement phase serves for determining whether the maintenance system is stable and capable (E\&E state). Moreover, this step enables various data distributions or distribution laws that are used in the simulation step. During the simulation phase, intuitive or with a formal optimization technique, the third step, process improvement, is performed. Finally, one stable and capable system may be artificially disturbed, allowing us to look into the simulated results and an expected future system response.

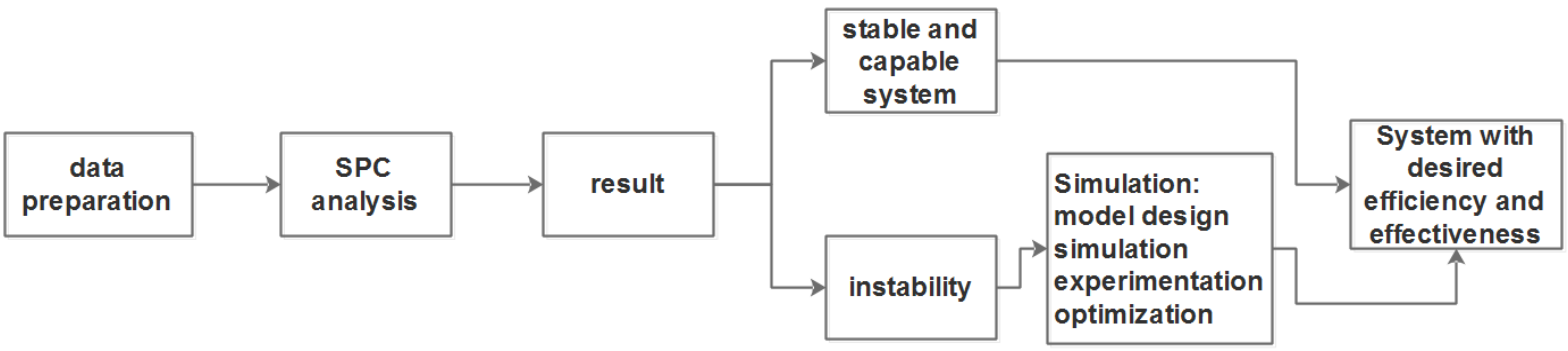

Figure 13: Overall MSIP methodology.

The optimization task is the most challenging step. Some authors have introduced the procedure called "Optimization via Simulation-OvS" into supply chain optimization problems (SCOP) [33]. We mention SCOP because of the strong influence of spare parts management in our model. Likewise, in maintenance, optimization is performed together with simulation [28-30]. Difficulties in optimization via simulation have three problems: (1) objective values are estimated with noise, (2) computational complexity, and (3) model complexity [31]. We used simulation as a specific Optimizer (Table III). Our simulation model is flexible and capable to cover a wide range of scenarios: different requirements, equipment, resources, different equipment usage dynamic and maintenance strategies, etc. The model functionality was demonstrated through a research case. The simulation model also enables experimentation. We were looking for two best criteria (KPIs): equipment availability and resources utilization. It is clearly demonstrated how this method (we suggest naming it MSIP - measure, simulate, improve and predict, see Fig. 13) is powerful and objective. Moreover, there are unlimited possibilities to calculate KPIs defined in EN 15341 Maintenance Maintenance Key Performance Indicators Standard. Our proposed method is consequently capable of functioning as an evaluation tool, a prediction tool, an optimization tool and a decision support tool. During designing the maintenance model, we discovered possibilities for implementing condition-based maintenance. This could be possible through a design probability-based failure generator. 


\section{CONCLUSION}

The measurement of maintenance effectiveness and efficiency, using SPC tools, is employed to determine the maintenance system stability and capability. When instability occurs in the maintenance process (for a specific equipment type), simulation is used to enable process transparency and dynamic behaviour understanding. With a simple change, for example, increasing (or arranging) the number of maintenance personnel, we can instantly change the maintenance system behaviour and effectiveness. When a reliable and accurate model is designed, this iterative procedure presents a form of optimization. Finally, such a model can be used for behaviour prediction. After some time, a certain event (an increase in the number of equipment, a decrease in the number of personnel, logistic time delays change, spare parts unavailability, etc.), can be set as an example, and then the effect on the maintenance system can become visible, and correction activities can be applied before real life system problems even occur. Simulations represent a growing trend in maintenance. But, as we found, little attention is paid to simulating complex maintenance systems. Moreover, we did not found a specific systematic approach to discovering problems before the simulation stage. The SPC technique is an extremely robust tool in business problem solving activities. The facts discovered with SPC tools, such as various laws of appearance, were used for discrete event simulation. The synergic value of this combination is demonstrated.

The modelling and simulation of a process is not an easy task. It requires good mathematical knowledge, understanding of the reliability theory and the concept of maintenance. However, investing in simulation knowledge offers an excellent opportunity to solve problems mentioned in the introduction, both in maintenance and other logistic fields.

The simulation model can be easily extended. This study is based on one army unit, but there are no boundaries to multiplying the model, only a different setup is required for any specific unit. This would allow for the creation of a wide (complete) maintenance model. It is clear that the solution is applicable in many areas, not only in army maintenance. The model can be expanded with additional modules for different purposes.

\section{REFERENCES}

[1] Gudehus, T.; Kotzab, H. (2012). Comprehensive Logistics, $2^{\text {nd }}$ edition, Springer-Verlag, Berlin

[2] Gulati, R. (2013). Maintenance and Reliability Best Practices, $2^{\text {nd }}$ edition, Industrial Press Inc., New York

[3] Starr, A.; Al-Najjar, B.; Holmberg, K.; Jantunen, E.; Bellew, J.; Albarbar, A. (2010). Maintenance Today and Future Trends, Holmberg, K.; Adgar, A.; Arnaiz, A.; Jantunen, E.; Mascolo, J.; Mekid, S. (Eds.). E-maintenance, Springer, London, 5-37

[4] Bousdekis, A.; Magoutas, B.; Apostolou, D.; Mentzas, G. (2015). A proactive decision making framework for condition-based maintenance, Industrial Management \& Data Systems, Vol. 115, No. 7, 1225-1250, doi:10.1108/IMDS-03-2015-0071

[5] Farnsworth, M.; Tomiyama, T. (2014). Capturing, classification and concept generation for automated maintenance tasks, CIRP Annals - Manufacturing Technology, Vol. 63, No. 1, 149152, doi:10.1016/j.cirp.2014.03.093

[6] Rastegari, A.; Salonen, A. (2015). Strategic maintenance management: Formulating maintenance strategy, International Journal of Condition Monitoring and Diagnostic Engineering Management, Vol. 18, No. 1, 5-14

[7] Roy, R.; Stark, R.; Tracht, K.; Takata, S.; Mori, M. (2016). Continuous maintenance and the future - Foundations and technological challenges, CIRP Annals - Manufacturing Technology, Vol. 65, No. 2, 667-688, doi:10.1016/j.cirp.2016.06.006

[8] Ab-Samat, H.; Kamaruddin, S. (2014). Opportunistic maintenance (OM) as a new advancement in maintenance approaches: A review, Journal of Quality in Maintenance Engineering, Vol. 20, No. 2, 98-121, doi:10.1108/JQME-04-2013-0018 
[9] Hasnida, A. S.; Shahrul, K.; Ishak, A. A. (2011). Maintenance performance measurement: A review, Pertanika Journal of Science and Technology, Vol. 19, No. 2, 199-211

[10] Parida, A.; Kumar, U. (2009). Maintenance Productivity and Performance Measurement, BenDaya, M.; Duffuaa, S.; Raouf, A.; Knezevic, J.; Ait-Kadi, D. (Eds.). Handbook of Maintenance Management and Engineering, Springer, London, 17-41

[11] Simões, J. M.; Gomes, C. F.; Yasin, M. M. (2011). A literature review of maintenance performance measurement: A conceptual framework and directions for future research, Journal of Quality in Maintenance Engineering, Vol. 17, No. 2, 116-137, doi:10.1108/ 13552511111134565

[12] Muchiri, P.; Pintelon, L.; Gelders, L.; Martin, H. (2011). Development of maintenance function performance measurement framework and indicators, International Journal of Production Economics, Vol. 131, No. 1, 295-302, doi:10.1016/j.ijpe.2010.04.039

[13] Kumar, U.; Galar, D.; Parida, A.; Stenström, C.; Berges, L. (2013). Maintenance performance metrics: a state of the art review, Journal of Quality in Maintenance Engineering, Vol. 19, No. 3, 233-277, doi:10.1108/JQME-05-2013-0029

[14] Tätilä, J.; Helkiö, P.; Holmström, J. (2014). Exploring the performance effects of performance measurement system use in maintenance process, Journal of Quality in Maintenance Engineering, Vol. 20, No. 4, 377-401, doi:10.1108/JQME-07-2013-0051

[15] Parida, A.; Kumar, U.; Galar, D.; Stenström, C. (2015). Performance measurement and management for maintenance: a literature review, Journal of Quality in Maintenance Engineering, Vol. 21, No. 1, 2-33, doi:10.1108/JQME-10-2013-0067

[16] Kao, C. (2015). Efficiency measurement for hierarchical network systems, Omega, Vol. 51, 121127, doi:10.1016/j.omega.2014.09.008

[17] Ouyang, C.; Wynn, M. T.; Fidge, C.; Hofstede, A. H. M.; Kuhr, J.-C. (2010). Modelling complex resource requirements in business process management systems, Proceedings of the $21^{\text {st }}$ Australasian Conference on Information Systems (ACIS), 11 pages, from http://aisel.aisnet.org/acis2010/60, accessed on 15-01-2017

[18] Vasilecas, O.; Smaizys, A.; Rima, A. (2013). Business process modelling and simulation: Hybrid method for concurrency aspect modelling, Baltic Journal of Modern Computing, Vol. 1, No. 3-4, 228-243

[19] Nagm-Aldeen, Y.; Abdel-Fattah, M. A.; El-Khedr, A. (2015). A literature review of business process modelling techniques, International Journal of Advanced Research in Computer Science and Software Engineering, Vol. 5, No. 3, 43-47

[20] Abreu, J.; Ventura Martins, P.; Fernandes, S.; Zacarias, M. (2013). Business processes improvement on maintenance management: a case study, Procedia Technology, Vol. 9, 320-330, doi:10.1016/j.protcy.2013.12.036

[21] Taheri, A.; Lazakis, I.; Turan, O. (2014). Integration of business and technical aspects of reliability and maintenance, Proceedings of the International Conference on Maritime Technology (ICMT 2014), 9 pages, from https://strathprints.strath.ac.uk/id/eprint/49020, accessed on 20-05-2017

[22] Oakland, S. J. (2003). Statistical Process Control, $5^{\text {th }}$ edition, Butterworth-Heinemann, Oxford

[23] Montgomery, D.C. (2009). Introduction to Statistical Quality Control, $6^{\text {th }}$ edition, John Wiley \& Sons, Inc., Hoboken

[24] Stapenhurst, T. (2005). Mastering Statistical Process Control, Elsevier, Butterworth-Heinemann, Amsterdam

[25] Alrabghi, A.; Tiwari, A. (2016). A novel framework for simulation-based optimization of maintenance systems, International Journal of Simulation Modelling, Vol. 15, No. 1, 16-28, doi:10.2507/IJSIMM15(1)2.316

[26] Alrabghi, A.; Tiwari, A. (2015). State of the art in simulation-based optimisation for maintenance systems, Computers \& Industrial Engineering, Vol. 82, 167-182, doi:10.1016/j.cie.2014.12.022

[27] Rao S. S. (2009). Engineering Optimization: Theory and Practice, $4^{\text {th }}$ edition, John Wiley \& Sons, Inc., Hoboken

[28] Alabdulkarim, A. A.; Ball, P. D.; Tiwari, A. (2013). Applications of simulation in maintenance research, World Journal of Modelling and Simulation, Vol. 9, No.1, 14-37 
[29] Jentsch, P.; Boukhtouta, A. (2015). A simulation study of military land equipment availability under corrective and preventive maintenance regimes, Proceedings of the $29^{\text {th }}$ European Conference on Modelling and Simulation (CECMS, 373-379

[30] Djokic, I.; Lazic, L.; Pavlovic, A.; Avdic, A. (2015). Simulation based life-cycle analysis of a vehicle fleet, Proceedings of the $2^{\text {nd }}$ Logistics International Conference, 216-221

[31] Xu, J.; Huang, E.; Chen, C.-H.; Lee, L. H. (2015). Simulation optimization: a review and exploration in the new era of cloud computing and big data, Asia-Pacific Journal of Operational Research, Vol. 32, No. 3, Paper 1550019, 34 pages, doi:10.1142/S0217595915500190

[32] Savić, V.; Knežević, D.; Lovrec, D.; Jocanović, M.; Karanović, V. (2009). Determination of pressure losses in hydraulic pipeline systems by considering temperature and pressure, Strojniski vestnik - Journal of Mechanical Engineering, Vol. 55, No. 4, 237-243

[33] Gocken, M.; Dosdogru, A.T.; Boru, A. (2017). Optimization via simulation for inventory control policies and supplier selection, International Journal of Simulation Modelling, Vol. 16, No. 2, 241-252, doi: 10.2507/IJSIMM16(2)5.375 